\title{
Timing and Severity of Postharvest Water Stress Affect Following-year Productivity and Fruit Quality of Field-grown 'Snow Queen' Nectarine
}

\author{
A. Naor \\ Golan Research Institute, P.O. Box 97, Kazrin 12900, Israel \\ R. Stern \\ MIGAL - Galilee Technology Center, P.O. Box 90000, Kiryat Shemona 12100, Israel
}

\author{
M. Peres, Y. Greenblat, and Y. Gal \\ Extension Service, Ministry of Agriculture and Rural Development, Kiryat Shemona 10200, Israel
}

Moshe A. Flaishman

Institute of Horticulture, Agricultural Research Organization, the Volcani Center, Bet Dagan 50250

Israel

\begin{abstract}
Aвstract. The effects of the timing and severity of postharvest water stress on the productivity and fruit quality of field-grown nectarine [Prunus persica $($ L.) Batsch cv. Snow Queen] were studied for two consecutive years. Three levels of postharvest water status (midday stem water potentials of $\mathbf{- 1 . 2}, \mathbf{- 2 . 0}$, and $\mathbf{- 2 . 8} \mathrm{MPa}$ ) were examined. They were designated as High, Med, and Low, respectively. In the second year two additional treatments were examined in which Low and Med water status were interchanged on 1 Sept. 2002, and these treatments were designated as Low/Med and Med/Low. The percentages of double fruits and of those having a deep suture increased with decreasing postharvest midday stem water potential during the previous year, and most of these defects were stimulated by water deficits that occurred prior to 1 Sept. Postharvest water stress led to decreased crop yield in the subsequent year because there were fewer fruits per tree. Flower buds with double pistils were first noticed in mid-September, and by mid-November the ranking of double pistils in the various treatments were similar to the ranking of double fruits measured a month after bloom in the subsequent season. Postharvest water stress delayed flower bud development. The percentage of double fruits increased from $10 \%$ in 2002 to $40 \%$ in 2003 and the higher percentage in 2003 was associated with higher air temperatures during the reproductive bud development stage in 2002 than in 2001 . Our data and others suggest that high temperatures create a potential for the occurrence of double fruits, but that the fulfillment of that potential is highly dependent on postharvest tree water status. The occurrence of double and deep suture fruits were highly correlated with midday stem water potential in August of the previous year, i.e., during the initial stages of flower bud development. The occurrence of double fruits was observed to increase sharply as the midday stem water potentials fell below -2.0 MPa, which suggests that a midday stem water potential of $-\mathbf{2 . 0} \mathrm{MPa}$ could serve as a threshold for postharvest irrigation scheduling.
\end{abstract}

The period between harvest and leaf fall might be a significant fraction of the irrigation season, especially for early- and midseason varieties, and growers tend to save water after harvest since no extensive growth is expected at this period. Severe water stress after harvest has been reported to affect both productivity and fruit quality in stone fruits (Behboudian and Mills, 1997; Naor, 2006), but there is insufficient quantitative analysis to determine the optimal degree of postharvest stress, i.e., the level that will maximize water saving while minimizing the impairment of productivity and fruit quality. This situation leaves the growers uncertain about postharvest irrigation scheduling.

In many cases the initial stages of bud development are observed before harvest (Tufts and Morrow, 1925; Westwood, 1993), and the development continues throughout the rest of the season. The occurrence of double fruits in peach (P.persica) and nectarine is related to postharvest water stress (Handley and Johnson, 2000; Johnson et al., 1992; Larson et al., 1988). Double fruits and those with a deep suture both result from postharvest water stress, and a significant decrease in the occurrence of double fruits in peach was reported when postharvest water stress was relieved at the beginning of August (Handley and Johnson, 2000). No double

Received for publication 9 Feb. 2005. Accepted for publication 11 May 2005. fruits were reported to result from severe postharvest water stress in japanese plum (P. salicina Lindl.) varieties (Johnson et al., 1994; Naor et al., 2004), which suggests that susceptibility to double fruiting may differ among species.

Severe postharvest water stress was found to decrease productivity in the subsequent year in apricot (P. armeniaca L.)(Brown, 1953; Ruiz-Sanchez et al., 1999; Torrrecillas et al., 2000; Uriu, 1964), peach (Girona et al., 2003), japanese plum (Johnson et al., 1994), and almond [P. dulcis (Mill.) Webb](Goldhamer and Viveros, 2000). Contrary findings of increased productivity in peach in the season following postharvest water stress (Johnson et al., 1992; Larson et al., 1988) were probably related to a lower level of stress and to pre-winter irrigation that had shortened the duration of the postharvest water stress.

The decrease in productivity caused by severe postharvest water stress was attributed to reduced flowering intensity (Brown, 1953; Girona et al., 2003) and lower fruit set (Girona et al., 2003; Goldhamer and Viveros, 2000; Ruiz-Sanchez et al., 1999; Torrecillas et al., 2000). The lower fruit set in apricot was attributed to reduced pollen vitality (Ruiz-Sanchez et al., 1999). Water stress has also been reported to delay flower bud development resulting in buds with smaller leaves surrounding, fruits with smaller pits, and delayed harvest (Brown, 1953). 
The objectives of the present study were to quantitatively evaluate the effects of timing and severity of postharvest water stress on the productivity and fruit quality of field-grown 'Snow Queen' nectarine.

\section{Materials and Methods}

Climatic conditions. The experimental site was in northern Galilee, Israel (lat. $33^{\circ} \mathrm{N}$, long. $36^{\circ} \mathrm{E}$ ), $350 \mathrm{~m}$ above mean sea level, in a semi-arid zone with no summer rain. The average annual precipitation (October-April) in this area is about $550 \mathrm{~mm}$.

EXPERIMENTAL ORCHARD. The experimental plot was an 8year-old, drip-irrigated, commercial orchard of 'Snow Queen' nectarine on $P$. persica seedling rootstock spaced at $4 \times 4.5 \mathrm{~m}$. The soil fraction comprised $57 \%$ clay, $35 \%$ silt, and $8 \%$ sand. The irrigation system consisted of two lateral lines per row, separated by $1.0 \mathrm{~m}$, with $2.3-\mathrm{L} \cdot \mathrm{h}^{-1}$ pressure-compensated in-line drippers (Netafim, Iftach, Israel), spaced at $0.5 \mathrm{~m}$.

Treatments. The experimental plot was irrigated until harvest, according to commercial practice: the cumulative water application amounts up to harvest were 312 and $386 \mathrm{~mm}$ in 2002 and 2003, respectively. After harvest, irrigation was intended to establish the various desired midday stem water potentials. In each treatment, irrigation was withheld until the desired midday stem water potential was achieved; thereafter, irrigation coefficients, expressed as percentages of the potential daytime evapotranspiration $\left(\mathrm{ET}_{0}\right)$ were changed empirically, twice per week, in response to the actual midday stem water potentials. Meteorological data collected $\approx 1$ $\mathrm{km}$ from the experimental plot were used for the calculation of Penman-Montieth $\mathrm{ET}_{0}$. Three irrigation treatments were applied after harvest in 2001 and 2002: low (-2.8 MPa), medium (-2.0 $\mathrm{MPa})$, and high $(-1.2 \mathrm{MPa})$ midday stem water potential. The treatments were designated as Low, Med, and High, respectively. Two additional treatments were examined in 2002. In order to test the timing at which nectarine is sensitive to postharvest water stress, the postharvest period was divided into two equal parts in which Low and Med water status were interchanged on 1 Sept. 2002. In the first treatment Low midday stem water potential was apparent until 1 Sept., followed by Med midday stem water potential, and in the second treatment Med midday stem water potential was apparent until 1 Sept., followed by Low midday stem water potential. The two treatments were designated as Low/Med and Med/Low, respectively. The treatments were replicated five times in a completely randomized block design. Measurements in each plot were taken on three or four trees surrounded by guard trees and rows receiving the same irrigation regime.

Midday STEM WATER POTENTIAL. Midday stem water potential was measured with a pressure chamber. Two shoot tips per tree were selected from the inner part of the canopy, and were enclosed, while still attached, in plastic bags covered with aluminum foil. After an equilibrating period of $90 \mathrm{~min}$, the shoot tips were detached from the shoot, and the stem water potential was determined immediately in the field with a pressure chamber (Ari-Mad; Kfar Charuv, Golan Heights, Israel). The two measurements were averaged before being subjected to statistical analysis.

Crop Measurements. The percentages of fruit set and of double fruits were monitored on marked shoots. Two shoots per tree were selected on three trees per plot in 2002, and four shoots per tree on three trees per plot in 2003. Ten flowers in succession were marked on each shoot and the numbers of all fruits and of double fruits were counted $30 \mathrm{~d}$ after full bloom (DAFB) and after June drop (81 DAFB). Commercial fruit thinning was performed except for the marked shoots: in order to maximize yields growers remove the smaller fruit of each double fruit. The crop was harvested on 9 and 13 June in 2002 and on 22 and 29 June in 2003. The fruit was weighed and the fruit size distribution was determined by means of a commercial sorting machine (NAF-57; NAF Montauban, France) at 5-mm increments in fruit diameter. In 2002, the fruits from the two harvest dates were grouped and an average of 89 fruits were randomly sampled from the $50-55 \mathrm{~mm}$ size grade (one tree per replicate). In 2003, an average of 285 fruits from each replicate were randomly sampled on the two harvest dates, before the fruit entered the sorting machine. The double fruits and those having a deep suture were counted; where the smaller component of a double fruit had been eliminated by the grower, the remaining fruit was counted as a double fruit.

DYNAMICS OF THE DEVELOPMENT OF PISTILS IN THE FLOWER BUDS. Twenty to 50 reproductive buds were collected randomly from each treatment in August, September, October, and November. The development of flower buds and double pistils was observed by means of binocular light microscopy. The samples were fixed in FAA solution (Bio-Lab, Jerusalem, Iarael), dehydrated in a graded ethanol series and embedded in Paraplast (Tyco Healtacare Group LP, Mansfield, Mass.). Sections were cut at $10 \mu \mathrm{m}$ thickness using a microtome (820 Spencer microtome; American Optical Corp., Buffalo, N.Y.), stained with Safranin and Fast-Green (Sigma Chemical Co., St. Louis), mounted in Permount (Fisher Scientific, Fair Lawn, N.J.) and examined with a Leitz Dialux 20 light microscope (Leica Microsystems, Heerebrugg, Switzerland), under bright field. In addition to the measurement of flower organ development, reproductive bud scalps were removed and the reproductive buds were cut through the middle with a razor blade and flower organ development was observed with a Leitz Dialux binocular microscope (Leica Microsystems); the lengths of the pistils of representative buds were determined.

Statistical analysis. Analysis of variance followed by Duncan's multiple range test were applied to the yield and quality data by means of the SAS GLM software (SAS Institute, Cary, N.C.) procedure. The difference in the proportion of double fruits between years was examined by means of SAS TTEST procedure. An exponential decay model was fitted to the double or deep-sutured fruits as a function of average midday stem water potentials in August, by means of the Sigmaplot (SPSS, Chicago).

\section{Results}

Weekly averages of postharvest daily irrigation levels and irrigation coefficients are presented in Fig. 1A-D. In the Low, Med and High treatments, the average irrigation coefficients (as fractions of $\mathrm{ET}_{0}$ ) over the period 1 Aug. to 15 Oct. were 0.14, 0.38 , and 1.08 , respectively, in 2001; and $0.01,0.37$, and 0.97 , respectively, in 2002. The cumulative postharvest irrigation levels in the Low, Med, and High treatments were 62, 231, and $699 \mathrm{~mm}$, respectively, in 2001; and 5.5,236, and $800 \mathrm{~mm}$, respectively, in 2002. The cumulative postharvest irrigation levels in the Low/ Med and Med/Low treatments in 2002 were 143 and $102 \mathrm{~mm}$, respectively. After harvest, the soil moisture content decreased gradually in the Low and the Med treatments (not shown) and it took $\approx 60$ and $\approx 30 \mathrm{~d}$, respectively, until the steady-state midday stem water potentials were attained in these treatments (Fig. $2 \mathrm{~A}-\mathrm{B})$. The same midday stem water potentials were apparent in all treatments in the spring of subsequent season (not shown).

The daily maximum temperatures increased gradually from 25 ${ }^{\circ} \mathrm{C}$ at the beginning of May to above $30{ }^{\circ} \mathrm{C}$ during July, August, 

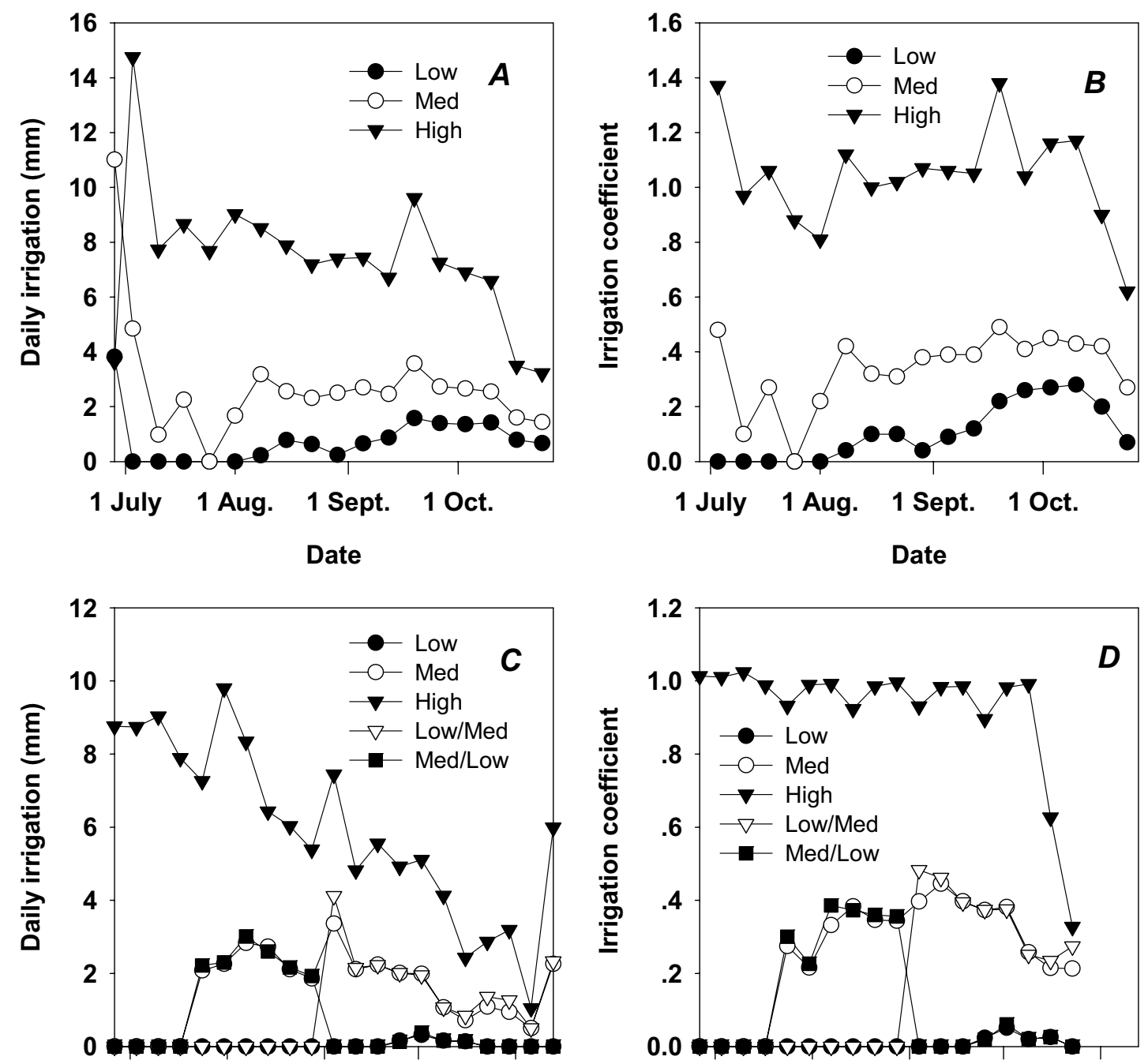

1 July 1 Aug. 1 Sept. 1 Oct. 1 Nov.

Date

1 July 1 Aug. 1 Sept. 1 Oct. 1 Nov.

Date

Fig. 1. Postharvest daily irrigation level and irrigation coefficient (fraction of $\mathrm{ET}_{0}$ ) in three irrigation treatments in 2001 (A, B) and five in 2002 (C, D). Midday stem water potentials of $-2.8 \mathrm{MPa},-2.0 \mathrm{MPa}$, and $-1.2 \mathrm{MPa}$ were maintained throughout the whole postharvest period in the Low, Med, and High irrigation treatments, respectively. Low/Med and Med/Low indicate midday stem water potentials that were interchanged on 1 Sept. 2002.

and September, and decreased gradually in October (Fig. 3A). The maximum air temperature rose above $30^{\circ} \mathrm{C}$ more frequently between mid-May and mid-June 2001, than during the corresponding period in 2002; however, there was an extreme hot period in early-June 2002, during which the air temperature rose above 35 ${ }^{\circ} \mathrm{C}$ on five consecutive days, with a peak level of $43.5^{\circ} \mathrm{C}$. Also in 2002 , there was an additional period at the end of July in which the maximum air temperature rose above $35^{\circ} \mathrm{C}$, and a few less extreme peaks between mid-September and mid-October. The average daily air temperature in the early-June, and late-July peaks in 2002 rose above $30{ }^{\circ} \mathrm{C}$ on three and four consecutive days, respectively (Fig. 3B).

Fruit set before harvest in 2002 increased with increasing 2001 postharvest irrigation level (Table 1), whereas the fruit set in 2003 was unaffected by the postharvest irrigation level in 2002. The double fruit percentage increased with decreasing previous-year irrigation level both in 2002 and 2003, and in the low irrigation treatment at 30 DAFB it was four times as great in 2003 as in 2002 (Table 1). The proportion of double fruits in 2003 was significantly higher than that in $2002(\alpha=0.003)$. In
2003 the double fruit percentage in the Low/Med treatment was significantly higher than that in the Med/Low treatment at 30 DAFB and showed the same trend at 81 DAFB.

The number of fruits per tree at harvest increased with increasing previous-year postharvest irrigation level in both 2002 and 2003 (Table 2). In the Low/Med and Med/Low treatments there were similar numbers of fruits per tree. The crop yield increased with increasing previous-year postharvest irrigation level (Table 2), but the differences were significant only in 2003. Commercial fruit thinning could mask the effect of the treatments, as the growers tend to thin double fruits before regular ones, but in the present case fruit thinning was minimal, so that there was a clear effect of the treatments. The Low/Med and Med/Low treatments had similar yields in 2003 (Table 2). The number of double fruits at harvest increased with decreasing previous-year postharvest irrigation level (Tables 1,2), and the effect of the Low treatment was more pronounced in 2003 than in 2002. The Low/Med treatment produced a higher percentage of doubles than the Med/Low treatment (Table 1). The percentage of fruits having a deep suture increased with decreasing previous-year postharvest irrigation 


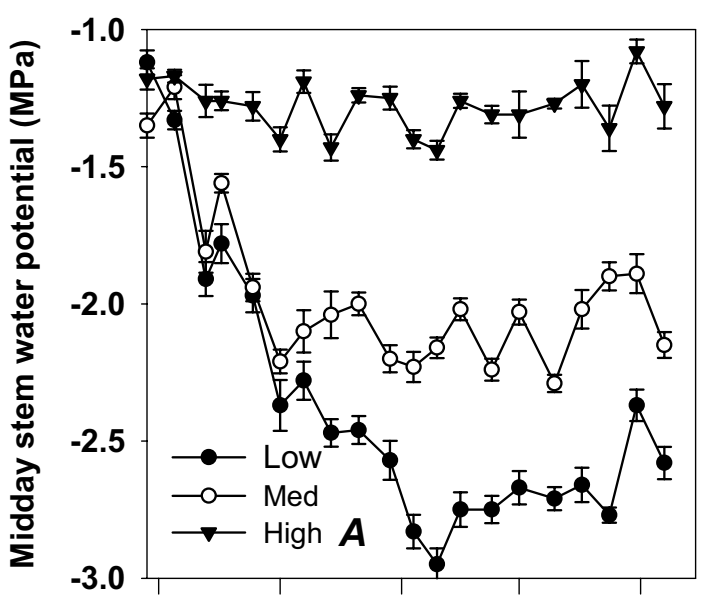

1 July 1 Aug. 1 Sept. 1 Oct. 1 Nov.

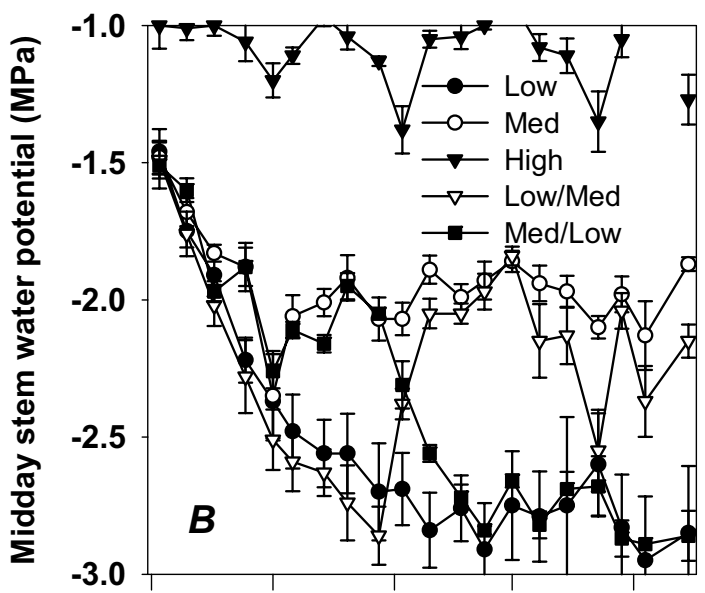

1 July 1 Aug. 1 Sept. 1 Oct. 1 Nov.

Date

Date

Fig. 2. Postharvest midday stem water potentials in three irrigation treatments in 2001 (A) and five in 2002 (B). Low (-2.8 MPa), Med ( $-2.0 \mathrm{MPa})$, and High ( -1.2 MPa). Low, Med, and High indicate midday stem water potentials that were maintained throughout the whole period. Low/Med and Med/Low indicate midday stem water potentials that were interchanged on 1 Sept. 2002.

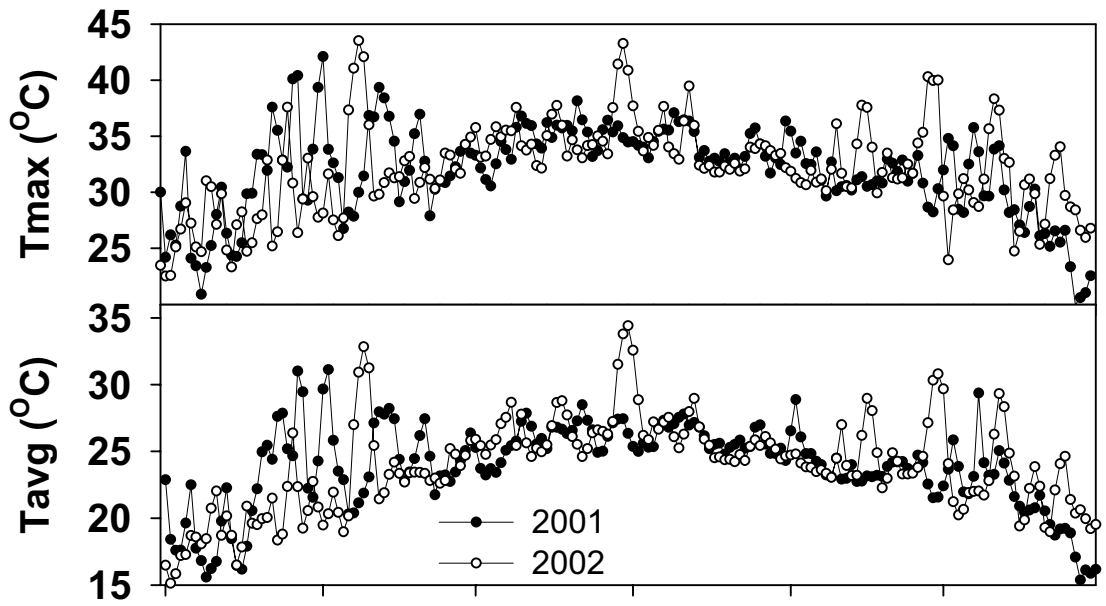

1 May 1 June 1 July 1 Aug. 1 Sept. 1 Oct.

Date

Fig. 3. Maximum (Tmax) and daily average (Tavg) air temperatures in 2001 and 2002.

Table 1. Percentage of fruit set and double fruits in nectarine 30 and $81 \mathrm{~d}$ after full bloom (DAFB) in 2002 and 2003 , in various postharvest irrigation regimes: Low $(-2.8 \mathrm{MPa})$, Med (-2.0 MPa), and High (-1.2 MPa). Low, Med, and High indicate midday stem water potentials that were maintained throughout the whole period. Low/Med, and Med/Low indicate midday stem water potentials that were interchanged on 1 Sept. 2002. In 2002, double fruit was not measured 81 DAFB.

\begin{tabular}{|c|c|c|c|c|c|c|c|}
\hline \multirow[b]{3}{*}{ Treatment } & \multicolumn{3}{|c|}{2002} & \multicolumn{4}{|c|}{2003} \\
\hline & \multicolumn{2}{|c|}{30 DAFB } & \multirow{2}{*}{$\begin{array}{c}81 \text { DAFB } \\
\text { Fruit set } \\
\text { (\% initial } \\
\text { flower no.) }\end{array}$} & \multicolumn{2}{|c|}{30 DAFB } & \multicolumn{2}{|c|}{81 DAFB } \\
\hline & $\begin{array}{l}\text { Fruit set } \\
\text { (\% initial } \\
\text { flower no.) }\end{array}$ & $\begin{array}{c}\text { Double } \\
\text { fruit (\% } \\
\text { remaining } \\
\text { fruit) }\end{array}$ & & $\begin{array}{c}\text { Fruit set } \\
\text { (\% initial } \\
\text { flower no.) }\end{array}$ & $\begin{array}{c}\text { Double } \\
\text { fruit ( } \% \\
\text { remaining } \\
\text { fruit) }\end{array}$ & $\begin{array}{l}\text { Fruit set } \\
\text { (\% initial } \\
\text { flower no.) }\end{array}$ & $\begin{array}{c}\text { Double } \\
\text { fruit (\% } \\
\text { remaining } \\
\text { fruit) }\end{array}$ \\
\hline Low & $71.2 \mathrm{~b}^{\mathrm{z}}$ & $10.3 \mathrm{a}$ & $21.0 \mathrm{~b}$ & $79.0 \mathrm{c}$ & $40.4 \mathrm{a}$ & $24.7 \mathrm{a}$ & $9.9 \mathrm{a}$ \\
\hline Med & $77.5 \mathrm{ab}$ & $4.8 \mathrm{a}$ & $26.3 \mathrm{~b}$ & $90.0 \mathrm{a}$ & $5.3 \mathrm{bc}$ & $26.5 \mathrm{a}$ & $1.9 \mathrm{ab}$ \\
\hline High & $86.8 \mathrm{a}$ & $0.0 \mathrm{~b}$ & $35.6 \mathrm{a}$ & $83.5 \mathrm{bc}$ & $0.8 \mathrm{c}$ & $29.4 \mathrm{a}$ & $0.0 \mathrm{~b}$ \\
\hline Low/Med & & & & $86.7 \mathrm{ba}$ & $29.5 \mathrm{a}$ & $25.8 \mathrm{a}$ & $7.8 \mathrm{a}$ \\
\hline Med/Low & & & & $85.2 \mathrm{abc}$ & $10.6 \mathrm{~b}$ & $28.2 \mathrm{a}$ & $3.9 \mathrm{ab}$ \\
\hline
\end{tabular}

${ }^{\mathrm{z}}$ Different letters within a column represent significant differences $\alpha<0.05$. 
Table 2. Total yield, number of fruits per tree, fruit weight, percentages of double fruits and of fruits with deep suture in nectarine in 2002 and 2003 related to the various postharvest irrigation regimes in the previous year: Low $(-2.8$ $\mathrm{MPa})$, Med (-2.0 MPa), and High (-1.2 MPa). Low, Med, and High indicate midday stem water potentials that were maintained throughout the whole period. Low/Med, and Med/Low indicate midday stem water potentials that were interchanged on 1 Sept. 2002.

\begin{tabular}{|c|c|c|c|c|c|c|c|c|c|c|}
\hline \multirow[b]{2}{*}{ Treatment } & \multicolumn{2}{|c|}{$\begin{array}{l}\text { Yield } \\
\left(\mathrm{t} \cdot \mathrm{ha}^{-1}\right)\end{array}$} & \multicolumn{2}{|c|}{$\begin{array}{c}\text { Fruit count } \\
\text { (no./tree) }\end{array}$} & \multicolumn{2}{|c|}{$\begin{array}{l}\text { Fruit wt } \\
(\mathrm{g})\end{array}$} & \multicolumn{2}{|c|}{$\begin{array}{c}\text { Double fruit } \\
\text { (\% harvested fruit) }\end{array}$} & \multicolumn{2}{|c|}{$\begin{array}{c}\text { Deep suture } \\
\text { (\% harvested fruit) }\end{array}$} \\
\hline & 2002 & 2003 & 2002 & 2003 & 2002 & 2003 & 2002 & 2003 & 2002 & 2003 \\
\hline Low & $46 \mathrm{a}^{\mathrm{z}}$ & $37 \mathrm{~b}$ & $915 \mathrm{~b}$ & $626 \mathrm{~b}$ & $91.1 \mathrm{a}$ & $106.7 \mathrm{a}$ & $3.4 \mathrm{ab}$ & $17.6 \mathrm{a}$ & $48.1 \mathrm{a}$ & $45.5 \mathrm{a}$ \\
\hline Med & $58 \mathrm{a}$ & $45 \mathrm{ab}$ & $1217 \mathrm{ab}$ & $798 \mathrm{ab}$ & $84.9 \mathrm{~b}$ & $104.8 \mathrm{a}$ & $5.8 \mathrm{a}$ & $3.08 \mathrm{c}$ & $28.1 \mathrm{ab}$ & $15.5 \mathrm{~b}$ \\
\hline High & $60 \mathrm{a}$ & $52 \mathrm{a}$ & $1272 \mathrm{a}$ & $918 \mathrm{a}$ & $85.5 \mathrm{~b}$ & $101.1 \mathrm{a}$ & $0.6 \mathrm{~b}$ & $0.0 \mathrm{~d}$ & $14.8 \mathrm{~b}$ & $9.0 \mathrm{~b}$ \\
\hline Low/Med & & $44 a b$ & & $738 \mathrm{ab}$ & & $106.7 \mathrm{a}$ & & $10.1 \mathrm{~b}$ & & $29.4 \mathrm{a}$ \\
\hline Med/Low & & $41 \mathrm{~b}$ & & $680 \mathrm{ab}$ & & $108.0 \mathrm{a}$ & & $5.6 \mathrm{bc}$ & & $30.6 \mathrm{a}$ \\
\hline
\end{tabular}

${ }^{\mathrm{z}}$ Different letters within a column represent significant differences $\alpha<0.05$

level in both 2002 and 2003, and this percentage was similar in the Low/Med and the Med/Low treatments (Table 2).

In August pistils were detected only in the High treatment, at a rate of $10 \%$ (Fig. 4A), but from September onwards pistils were observed in $100 \%$ of the reproductive buds in that treatment (Fig. 4A). In September no pistils were observed in the Low treatment, and in the other treatments the percentages of buds with pistils increased with increasing midday stem water potential, and in November pistils were observed in all the buds of all the treatments. In September the length of the pistils was $0.3 \mathrm{~mm}$ in the High treatment and extremely small in the other treatments (Fig. 4C), and in November the pistils in the High treatment were longer than those in the other treatments. Flower buds with double pistils were first noticed in mid-September (Fig. 4B), and by mid-November the ranking of double pistils in the various treatments were similar to the ranking of double fruits measured a month after bloom in the subsequent season (Table 2). In the Med treatment the proportion of flower buds with double pistils reached its maximum as early as October (Fig. 4B), i.e., sooner than in the more severe water stress treatments. The difference between the proportions of double pistils in the Med treatment and in the more stressed treatments increased from October to November.

The percentage of double fruits in 2003 increased exponentially as the average midday stem water potential in the previous August (2002) decreased (Fig. 5). There was a slight increase in the occurrence of double fruits up to $-2.0 \mathrm{MPa}$, followed by a significant increase as the midday stem water potential continued to decrease. The percentage of double fruits decreased from 30 April to 20 June 2003, especially at low midday stem water potentials. The percentage of deeply sutured fruits in 2003 increased exponentially as the midday stem water potential in the previous August (2002) decreased (Fig. 6).

\section{Discussion}

Postharvest water stress decreased the number of fruits at harvest of the subsequent season (Table 2), in contrast to reported findings for peach (Johnson et al., 1992; Larson et al., 1988). In the present study, the flower intensity in the stressed trees appeared, visually, to be similar to that in the control trees, unlike what was reported for peach (Johnson et al., 1992); the trees in the present Low treatment were more stressed than the stressed trees in the Johnson et al. (1992) and Larson et al. (1988) experiments; the much lower irrigation rates in the present experiment could have caused more damage to the flower buds. The lower flower intensity (Johnson et al., 1992) and lower fruit set (Larson et al., 1988) in unstressed peach could have occurred because the reproductive buds in the growing shoots remain immature for longer time in non stressed trees, resulting in flower buds that are not fully developed in subsequent year.

Fruit weight in the stressed trees was higher than that in the
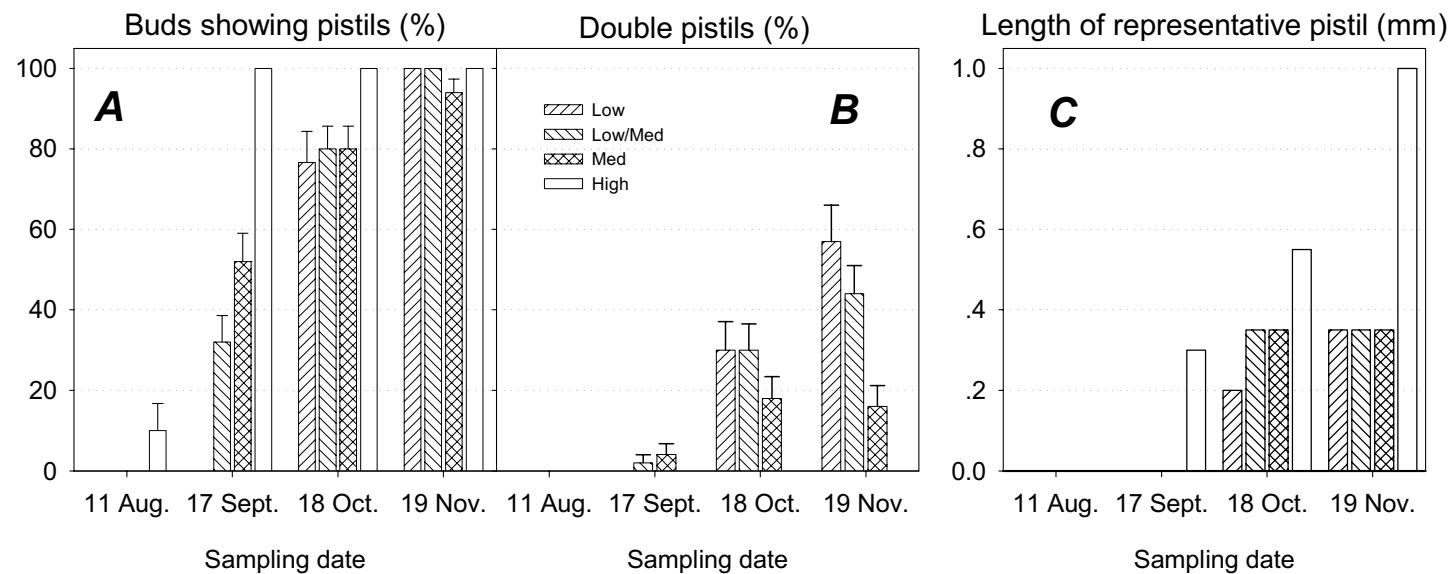

Fig. 4. Formation dynamics of all pistils (one and double) (A) and double-pistils (B), and the lengths of representative pistils $(\mathbf{C})$ in nectarine during the postharvest period in 2002, in response to four postharvest irrigation treatments examined in 2002. Midday stem water potentials of $-2.8 \mathrm{MPa},-2.0 \mathrm{MPa}$, and $-1.2 \mathrm{MPa}$ were maintained throughout the whole postharvest period in the Low, Med, and High irrigation treatments, respectively. In the Low/Med treatment the midday stem water potentials were interchanged on 1 Sept. 2002. 


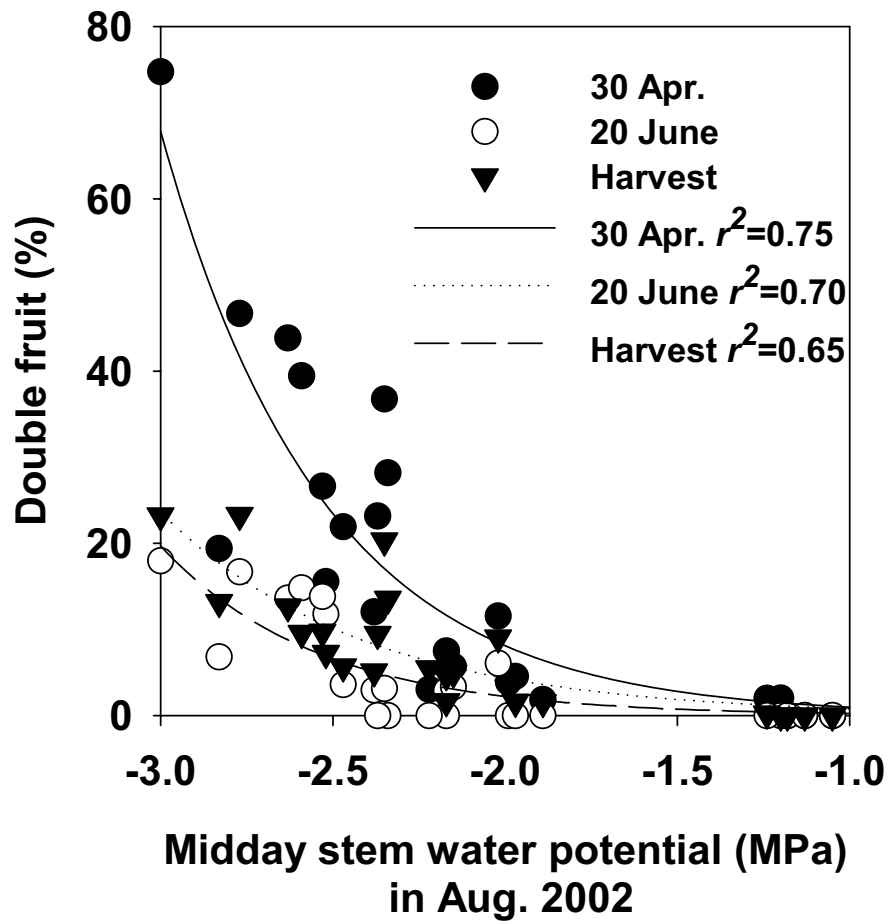

Fig. 5. Percentages of double fruits (\% remaining fruit) in nectarine on $30 \mathrm{Apr}$. 2003, 20 June 2003, and at harvest (22 and 29 June 2003) as a function of average midday stem water potential in August in the previous year (2002).

High treatment in 2002 but not in 2003 (Table 2). It seems that the extremely high crop load in the Med and High treatments in 2002 caused a significant limitation in the availability of assimilates which, in turn, resulted in smaller fruit weight, similarly to what was reported previously (Berman and DeJong, 1996; DeJong and Grossman, 1995; Grossman and DeJong, 1995; Naor et al., 2001).

Severe postharvest water stress here increased the occurrence of double fruits (Tables 1 and 2) similar to former reports in peach (Handley and Johnson, 2000; Johnson et al., 1992). These clearly show that postharvest water stress is involved in the formation of double fruits in peach. However, no double fruits were reported in field-grown japanese plum in response to severe postharvest water stress (Johnson et al., 1994; Naor et al., 2004) and postharvest water stress did not increase the occurrence of double pistils in cherry (P. avium L.) in controlled environment (Beppu and Kataoka, 1999; Beppu et al., 2001). Although there are no comparative studies on the response of stone fruit species to postharvest water stress, the cumulative data may suggest that stone fruit species respond differently to postharvest water stress.

The proportion of double fruit decreased along the season (Table 1) similar to other report (Johnson et al., 1992) suggesting that the tendency of double fruit to drop is higher than that of regular fruit. The proportion of double fruit in 2003 was much higher than what has been reported elsewhere (Johnson et al., 1992) probably due to insufficient fruit thinning here and due to the tendency of the grower to eliminate the smaller fruit of the double (counted here as double fruit) instead of removing the whole double fruit.

The percentage of double fruits was four times as great in 2003 than in 2002; this was probably related to a few extreme hot periods in 2002, in which the average air temperature rose above 30 ${ }^{\circ} \mathrm{C}$ for three to five consecutive days (Fig. 3), and it may suggest

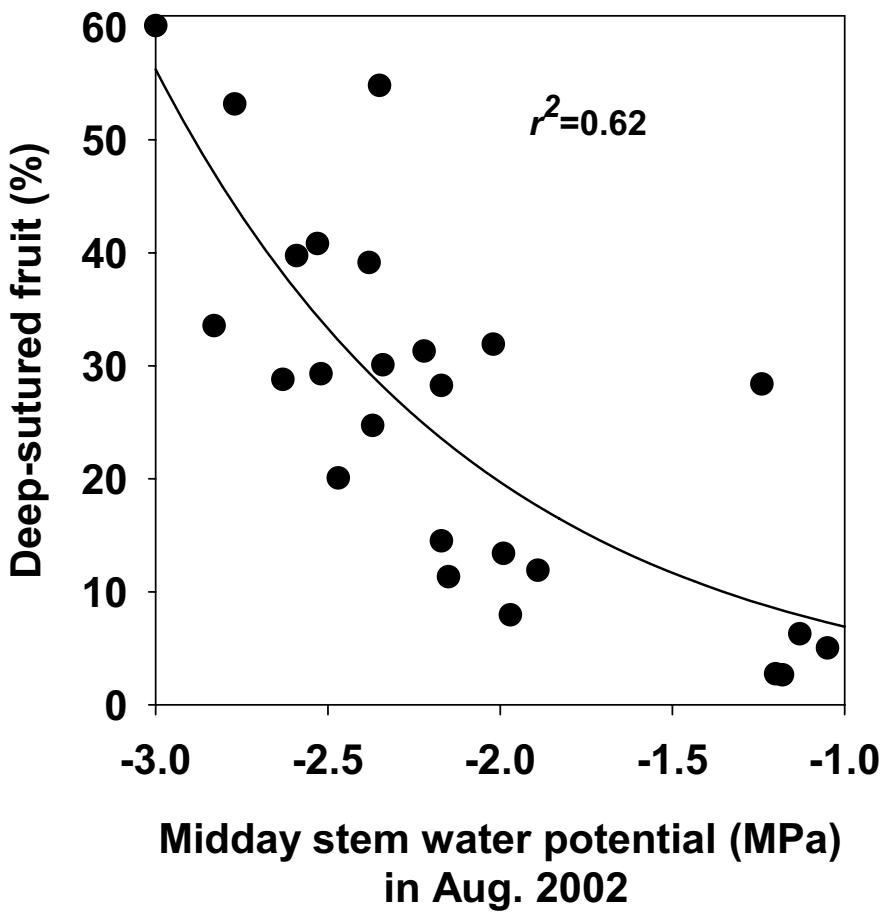

Fig. 6. Percentages of deeply sutured fruit at harvest in nectarine in 2003 as a function of average midday stem water potential in August in the previous season (2002).

that the occurrence of double fruit is affected by air temperature in the bud development stage, as has been reported for peach (Johnson et al., 1992). Detailed studies in cherry reported that the percentage of double fruits increased with increasing temperature above $30{ }^{\circ} \mathrm{C}$ (Beppu and Kataoka, 1999; Beppu et al., 2001) in a controlled environment, and it decreased in field-grown cherry trees under shade netting that reduced the air temperature (Beppu and Kataoka, 2000).

Our findings and others show that both temperature (Beppu and Kataoka, 1999; Beppu et al., 2001; Johnson et al., 1992) and post harvest water stress (Handley and Johnson, 2000; Johnson et al., 1992) are responsible for the occurrence of double fruits. It seems that flower buds exposed to high temperature during the bud development stage acquire the potential to form double fruits, but that the proportion of buds that realized this potential was strongly affected by postharvest water stress.

Our present data show that postharvest water stress caused higher proportion of double fruits when it occurred before the beginning of September (Table 1), and this is supported by the finding that more double fruits occurred in peach when water stress was relieved from 18 Aug. to $27 \mathrm{Sept}$. in 1 year than when it was relieved from 1 Aug. to 10 Sept. in another year (Handley and Johnson, 2000). Thus, it appears that the major effect of water stress in eliciting double fruit formation occurs before the beginning of September, before any visible anatomical effects could be detected. In peach and nectarine, the susceptibility to the formation of double fruit buds in response to water stress ended later than was reported for cherry in response to high temperature stress, i.e., late July (Beppu et al., 2001). It should be noted that temperature and water stress indirectly affect each other: air temperature is highly correlated with relative humidity and, therefore, with vapor pressure deficit, which, in turn, is known to affect the midday water potential (McCutchan and Shackel, 
1992); also, the stomatal conductance decreases and therefore the canopy temperature increases as a result of increasing water stress (Naor, 1998). This interaction highlights the need to evaluate both canopy temperature and plant water status, irrespective of which factor is under study.

In the present study the period of high sensitivity to water stress occurred 30-60 d before significant anatomic changes became visible (Fig. 4). Water stress delayed flower bud development, as reflected in the development dynamics and the size of the pistils (Fig. 4), similar to findings reported for apricot (Brown, 1953).

Handley and Johnson (2000) showed a peach with a deep suture that contained a degenerated double fruit, which clearly could not have formed the suture physically; and concluded that both the double fruit and the deep suture represented a phenotype that arose from the formation of double carpel and double pistils. In the present study, we observed a small pedicle emerging from a split in the pit of a deeply sutured fruit; the small pedicle had originated from the pedicle of the fruit (not shown), and this may support the above conclusion of Handley and Johnson (2000).

Our data show significant increases in the occurrence of double fruits when the midday stem water potential in the preceding August decreased below -2.0 MPa (Fig. 5), which may indicate that -2.0 MPa could serve as a threshold value of midday stem water potential, for postharvest irrigation scheduling. The proportion of deep-sutured fruit at $-2.0 \mathrm{MPa}$ is quite high (Fig. 6) and therefore higher threshold should be considered in cases where the economical damage due to deep sutured fruit is significant.

\section{Literature Cited}

Behboudian, M.H. and T.M. Mills. 1997. Deficit irrigation in deciduous orchards. Hort. Rev. 21:105-131.

Beppu, K. and I. Kataoka. 1999. High temperature rather than drought stress is responsible for the occurrence of double pistils in 'Satohnishiki' sweet cherry. Sci. Hort. 81:125-134.

Beppu, K. and I. Kataoka. 2000. Artificial shading reduces the occurrence of double pstils in 'Satohnishiki' sweet cherry. Sci. Hort. 83:241-247.

Beppu, K., T. Ikeda, and I. Kataoka. 2001. Effect of high temperature exposure time during flower bud formation on the occurrence of double pistils in 'Satohnishiki' sweet cherry. Sci. Hort. 87:77-84.

Berman, M.E. and T.M. DeJong. 1996. Water stress and crop load effects on fruit fresh and dry weights in peach (Prunus persica). Tree Physiol. 16:859-864.

Brown, D.S. 1953. The effect of irrigation on flower bud development and fruiting in the apricot. Proc. Amer. Soc. Hort. Sci. 61:119-124.

DeJong, T.M. and Y.L. Grossman. 1995. Quantifying sink and source limitations on dry matter partitioning of fruit growth in peach trees. Physiol. Plant. 95:437-443.

Girona, J., M. Mata, A. Arbonés, S. Alegre, J. Rufat, and J. Marsal. 2003. Peach tree response to single and combined regulated deficit irrigation regimes under shallow soils. J. Amer. Soc. Hort. Sci. 128:432-440.

Goldhamer, D.A. and M. Viveros. 2000. Effects of preharvest irrigation cutoff durations and postharvest water deprivation on almond tree performance. Irrig. Sci. 19:125-131.

Grossman, Y.L. and T.M. DeJong. 1995. Maximum fruit growth potential and seasonal patterns of resource dynamics during peach growth. Ann. Bot. 75:553-560.

Handley, D.F. and R.S. Johnson. 2000. Late summer irrigation of water stressed peach trees reduces fruit doubles and deep sutures. Hortscience 35:771.

Johnson, R.S., D.F. Handley, and T.M. DeJong. 1992. Long-term response of early maturing peach trees to post harvest water deficits. J. Amer. Soc. Hort. Sci. 117:881-886.

Johnson, R.S., D.F. Handley, and K.R. Day. 1994. Postharvest water stress of an early maturing plum. J. Hort. Sci. 69:1035-1041.

Larson, K.D., T.M. DeJong, and R.S. Johnson. 1988. Physiological and growth responses of mature peach trees to postharvest water stress. J. Amer. Soc. Hort. Sci. 113:296-300.

McCutchan, H. and K.A. Shackel. 1992. Stem-water potential as a sensitive indicator of water stress in prune trees (Prunus domestica L. cv. French). J. Amer. Soc. Hort. Sci. 117:607-611.

Naor, A. 1998. Relationships between leaf and stem water potentials and stomatal conductance in three field-grown woody species. J. Hort. Sci. Biotechnol. 73:431-436.

Naor, A. 2006. Irrigation scheduling and evaluation of tree water status in deciduous orchards. Hort. Rev. 32:111-166.

Naor, A., H. Hupert, Y. Greenblat, M. Peres, and I. Klein. 2001. The response of nectarine fruit size and midday stem water potential to irrigation level in stage III and crop load. J. Amer. Soc. Hort. Sci. 126:140-143.

Naor, A., M. Peres, Y. Greenblat, Y. Gal, and R. Ben Arie. 2004. Effects of pre-harvest irrigation regime and crop level on yield, fruit size distribution and fruit quality of field-grown 'Black Amber' Japanese plum. J. Hort. Sci. Biotechnol. 79:281-288.

Ruiz-Sanchez, M.C., J. Jega, R. Galego, and A. Torrecilas. 1999. Floral biology of 'Bulida' apricot trees subjected to post harvest drought stress. Ann. Appl. Biol. 135:523-528.

Torrecilas, A., R. Domingo, R. Galego, and M.C. Ruiz-Sanchaiz. 2000. Apricot tree response to withholding irrigation at different phenological periods. Scientia Hort. 85:201-215.

Tufts. W.P. and E.B. Morrow.1925. Fruit bud differentiation in deciduous fruits. Hilgardia 1:3-14.

Uriu, K. 1964. Effect of post-harvest soil moisture depletion on subsequent yield of apricots. Proc. Amer. Soc. Hort. Sci. 84:93-97.

Westwood, M.N. 1993. Temperate-zone pomology. Timber Press, Portland, Ore. 